\title{
Reform in Education of Traditional Chinese Medicine Knowledge Integration into Department of Food Quality and Safety
}

\author{
Huayi Suo ${ }^{1, a}$, Ruokun $\mathrm{Yi}^{2, b}$ and Yu Qian ${ }^{2, \mathrm{c}^{*}}$ \\ ${ }^{1}$ College of Food Science, Southwest University, Chongqing 400715, China \\ ${ }^{2}$ Department of Biological and Chemical Engineering, Chongqing University of Education, \\ Chongqing 400067, China
}

abirget@swu.edu.cn, byiruokun1214@hotmail.com, ' qianyubaby@126.com, *Corresponding author

Keywords: education, traditional Chinese medicine, department of food quality and safety

\begin{abstract}
The cultivation of applied talents is strengthened through the teaching reform which refers to adding the knowledge on homology of medicine and food into food quality and safety major. Reach the international standard in line of Chinese social demand in nowadays. In order to realize the knowledge fusion between the homology of medicine and food and the food quality and safety major, the teaching reform is implemented through three aspects, namely theory teaching, experimental practice and cultivation of application and development ability to make homology of medicine and food as the important teaching component. The homology of medicine and food not only is the important content in traditional Chinese medicine but also has been integrated into the industry of health food. To add the knowledge on homology of medicine and food into food quality and safety major can make students to grasp the knowledge of multiple disciplines and become the applied talents needed by the society.
\end{abstract}

\section{Introduction}

Food quality and safety is an important major in Chinese food specialty as well as a cross major based on bioscience and food science. In addition, it is a major highly related to food nutrition and food hygienic quality control through analysis of relationship between food nutrition and food safety and health. It is an important discipline to connect food science and preventive medicine. In recent years, many serious issues in food quality and safety have appeared in China. Meanwhile, "food quality and safety major" also has attracted extensive attention from the society. The major scale is expanding gradually. The sharp rise has appeared in the number of students. At present, it is in a period of high development.

In China, universities and colleges are all provided with food quality and safety major, including science, engineering, agriculture, medicine and normal universities and colleges etc. The top three colleges in the number of recruit students are agricultural colleges, engineering colleges and medical colleges successively[2, 3]. There is a great difference in curriculum setting, teaching level and cultivation target due to their different discipline backgrounds. Consequently, it is necessary to make an in-depth teaching reform on how to cultivate the applied talents to meet the social demand in food quality and safety major [4]. In order to cultivate the applied talents with multi-disciplinary combining capacity in line with the social demand, how to better construct food quality and safety major is a research subject needed urgently.

\section{Contents of teaching reform}

In the developed countries, there is no food quality and safety major in the system of universities and colleges [5]. In addition, the major close to traditional Chinese medicine in foreign universities and colleges only is provided with Korean medicine. Therefore, there is no international advanced experience as reference for the teaching reform on how to combine the homology of medicine and food with the food quality and safety major. It is a necessary to carry out the reform in accordance with Chinese characteristics and the actual backgrounds of universities and colleges. In order to 
integrate the knowledge on advantageous homology of medicine and food into the food quality and safety major, the teaching reform will be implemented from three aspects, namely theory teaching, experimental practice and application and development.

Reform of theory teaching. First, when designing theoretical courses, add the theoretical courses related to the knowledge on homology of medicine and food, including traditional Chinese medicine, natural plant resource and pharmacology etc. But the relevant courses added are not only the simple course adding in the teaching but also the combination between the contents of these courses and the food quality and safety. Combine the resource of homology of medicine and food with nutrition and health care to compile the new teaching material and carry out the teaching in line with the multi-disciplinary-combining teaching plan. Meanwhile, the teachers also should have the knowledge of multi-disciplinary background in food, nutrition and traditional Chinese medicine etc., and capable of integrating the theoretical knowledge combining the resource of homology of medicine and food with nutriology and physiology into the original food quality and safety major.

In addition of adding part of new theoretical courses, integrate the knowledge on homology of medicine and food into the original theoretical course of food quality and safety major. For instance, supplement the description on resource of homology of medicine and food in the food resources course. In addition, add more descriptions on functional effect of resource of homology of medicine and food in the functional food course, and integrate the content of functional food on resource of homology of medicine and food into the course related to food processing.

In a word, integrate the theoretical knowledge related to the homology of medicine and food into the theoretical teaching of food quality and safety major to realize the knowledge grasp on homology of medicine and food in students. In addition, take the knowledge on homology of medicine and food as an important part of theoretical teaching in the food quality and safety major combined by multiple disciplines.

Reform of experimental practice. In addition of theoretical course, experimental practice course also plays an important role in science and engineering major. Consequently, in addition of the relevant teaching reform in theoretical course, the reform also should be implemented in the experimental practice course of food quality and safety major so as to better integrate the knowledge on homology of medicine and food. Different from the content of homology of medicine and food added in the theoretical course, it is not only to simply add the relevant content in the experimental practice course. What's more is to reform the original practice course and fully integrate the content into the most of original experimental practice courses of food quality and safety major.

In the experimental practice course, replace the part of original food experiment samples with the close homology sample of medicine and food firstly. For instance, replace citrus with lotus seed to conduct the experiment of drink making in the experiment of food technology. In addition, replace fruit with jujube to conduct the experiment of vitamin $C$ determination in the experiment course of food physical and chemical analysis. Secondly, integrate the relevant knowledge into the experimental and testing standards and methods. For instance, integrate the experiment of pharmacology into the experimental course of toxicology. In case of change in testing target, the corresponding experimental method and testing standard also should be changed. Finally, integrate the experimental methods commonly used in pharmacy and medical majors into the experimental practice course of food quality and safety major, such as animal experiment and experimenting on human being etc.

In China, most of well-known enterprises producing health food are pharmaceutical enterprises. In addition, most of them are related to traditional Chinese medicine, such as Sanjing Pharmaceutical, Joincare Pharmaceutical Group, Jiuzhitang Group Co. Ltd and Taiji Group etc. Moreover, most of the others are the science-and-technology enterprises based on bio-pharmacy technology. The traditional food enterprise is very few. This system is obviously different with the foreign health food enterprise. Consequently, when the students learning food quality and safety major with the cultivating target of nutrition and health care, the most of health food enterprises they will face are the pharmaceutical enterprises related to traditional Chinese medicine and other resources of homology of medicine and 
food. In actual practice, the original practice platform should be transformed to the pharmaceutical enterprise and biology science-and-technology enterprise having the production capacity of health food from the traditional food enterprise. In the process of practice, combine the learned knowledge on food major with the traditional Chinese medicine (homology of medicine and food) culture and technology, and exercise the personal practical ability.

Reform on cultivation of application and development abilities. The undergraduate education in China is the system focused on foundation course education. The students are lack of the ability to make research and development in enterprises. Under the background to cultivate the applied talents, the target is to make students to become the talents needed by enterprises immediately when they entering the society. Consequently, the applied talents with some research and development abilities in food quality and safety major are the personnel needed by the food industry. Moreover, the talents with the knowledge and the research and development abilities in homology of medicine and food are the high value-added personnel, who are urgently needed by the health food enterprises capable of entering the international market.

The teachers of traditional food major are lack of the research and development abilities in nutriology and physiology etc. The reform should be implemented from the aspect of teachers firstly. The teachers are required to break through the research scope of traditional food major and strengthen their improvement of research ability in traditional Chinese pharmacology, pharmacology and nutriology etc. They should own the ability to fully integrate the resource of homology of medicine and food into the food development and research. In order to cultivate the applied talents needed by the society, the teachers should enter the research and development institute firstly to practice and improve their own teaching and researching abilities. After the teaching level of teacher meets the requirement, it is necessary to promote the students to participate in the research and development as much as possible. To establish the student's scientific research project related to homology of medicine and food in health food and implement the innovative practice activities and entrepreneurial activities are both the methods to cultivate the students of food quality and safety major in the college period. Strengthen the student's ability to use the resource of homology of medicine and food to develop health food and research its effect as well as enhance the effect of health food through scientific research project and innovation and entrepreneurship etc. so as to lay a foundation for entering society and enhance their society competitive.

\section{Summary}

As an important component in traditional Chinese medicine, the homology of medicine and food not only exists in the pharmaceutical industry but also has integrated into the health food industry. To add the teaching content of homology of medicine and food into the food quality and safety major makes the students to grasp the multi-disciplinary knowledge including food science, pharmacy and nutriology etc., which contributes to the cultivation of applied talents adapt to the modern social need.

\section{Acknowledgement}

This research was financially supported by the Teaching Reform Research Project Transformation Research Project of Chongqing University of Education (ZXJG03).

\section{References}

[1] Y.D. Shen, C.H. Liu, Y.M. Sun, Q. Wu, Z.L. Xiao, Development and concept of food quality and safety major, Food Mach. 2014 (2014) 264-267.

[2] L.W. Jiang, H.L. Zhou, S.C. Liu, F.M. Deng, Y.B. Xia, Thinking of how to establish the specialty of "Food quality and safety", J. Food Safe. Qual. 2 (2011) 218-222.

[3] A.X. Huang, J.X. Gong, W. Yuan, Thoughts on the specialty construction of food quality and safety characteristic, High. Agri. Educ. 6 (2011) 48-50. 
[4] M. Zhang, X.S. Xiao, Y.S. Xia, J.B. Dong, Thinking on the research of the target and quality standard of the professional application of food quality and safety, China Educ. Light Ind. 2010 (2010) 34-37.

[5] Z.Z. Rao, Practice and Thinking on the reform of university course examination, J. Hubei Univ. Econ. (Humanities Soc. Sci.) 2007 (2007) 166-167. 